\title{
Home and community literacy experiences of individuals with Down syndrome
}

\author{
Brian Trenholm, M.Ed., M.A. and Pat Mirenda, Ph.D. \\ University of British Columbia \\ Vancouver, BC Canada
}

\begin{abstract}
This exploratory survey was conducted to gain a detailed understanding of the home and community literacy experiences of children, adolescents and adults with Down syndrome. The data were collected from 224 parents/guardians across Canada who were asked to indicate literacy goals and priorities for their children with Down syndrome, the literacy resources they and their children utilised at home and in the community, perceived barriers to their children's literacy attainment, and solutions for alleviating the barriers. The results were analysed according to age when appropriate, in order to better understand the course of literacy development. Overall, the number of respondents who indicated their children with Down syndrome could read and write appeared to be consistent with previously published estimates, including the number reporting advanced reading levels. The wide range of reading and writing materials observed in use at home appeared to be greater than the range of materials actually used by children with Down syndrome. Relatively few of the parents who read storybooks to their children reported asking higher-level questions, suggesting that some parents might benefit from support in this activity. Many respondents reported using the library, and many expressed concerns about the quality and scarcity of literacy programs. The results are discussed with regard to their implications for how parents, caregivers, teachers, and program providers can encourage literacy development in persons with Down syndrome, and suggestions for future research.
\end{abstract}

Keywords: reading, writing, literacy, home experiences, community experiences, Down syndrome

Literacy development plays an important role in the lives of people both with and without disabilities, and many factors contribute to the attainment of literacy skills. People with disabilities such as Down syndrome often struggle to learn to read and write and are sometimes viewed as incapable of attaining literacy, despite arguments such as Siegel's (1989) that "there is no evidence that lower IQ scores are causally related to poor reading skills." Snowling and Gombert (2002) argued that, since the research base regarding literacy development in typically developing readers is quite well established, more effort should be focused on determining how children with impaired cognitive abilities learn to read, given their greater need for skilled intervention.

Some educators and researchers have suggested that whole word (i.e., sight word) approaches are most effective for supporting the literacy development of people with Down syndrome, in light of their relatively strong visual processing skills (Buckley, 1985, 1995; Cossu et al., 1993; Greene, 1987; Norris, 1989; Oelwein, 1995). More recent research supports the use of instructional approaches that focus on the development of phonological awareness skills (e.g., Car-
doso-Martins et al., 2002; Cupples \& Iacono, 2000, 2002; Fletcher \& Buckley, 2002; Fowler et al., 1995; Gombert, 2002; Kennedy \& Flynn, 2003; Snowling et al., 2002). Fowler et al. found a strong relationship between visual memory and reading ability, and concluded that phonological awareness and visual memory both make important but distinct contributions to the development of reading ability in people with Down syndrome. Increasingly, a balanced middle position that values the contribution of both approaches appears to hold the most promise (Al Otaiba \& Hosp, 2004; Gallaher et al., 2002; Morgan et al., 2004; Moni \& Jobling, 2000, 2001).

Chall (1983) proposed that learning to read involves progressing through a series of hierarchical stages and that progress through these stages is determined by interactions between individuals and their environments. During stage 0 (ages 6 months to 6 years), the child 'pretends' to read, retells a story after being read to, names letters of the alphabet, and plays with reading and writing materials. In stage 1 (ages 6 and 7 years), the child learns to associate letters and letter combinations with the sounds they repre- 
sent, begins to decode simple words, and reads simple texts. During stage 2 (ages 7 and 8 years), basic reading skills are consolidated and reading fluency increases. Collectively, the general focus in the first three stages can be thought of as 'learning to read.' The transition to stage 3 usually begins in grade 4 , and this stage is not completely traversed until the high school years. In a sense, this is a 'watershed' stage and is especially significant because it requires readers to shift from learning to read to 'reading to learn.' Chall observed that readers who do not make this shift successfully are often considered functionally illiterate, with reading abilities that are limited to familiar materials that do not extend beyond the person's existing knowledge and vocabulary. In light of this, Spear-Swerling and Sternberg (1996) suggested that it would be beneficial to consider how school, home, and community variables interact to affect reading development across the lifespan.

Some researchers have examined the relationship between literacy and school variables in adolescents and young adults with Down syndrome. For example, Bochner et al. (2001) investigated the functional literacy skills of 30 individuals with Down syndrome (ages 18 to 36 ) who lived at home with their families. They found a positive relationship between literacy development and age for participants born after 1970, and between literacy development and school placement for participants who spent all or most of their school careers in general education or partially integrated classrooms located in regular schools. In a related ethnographic study, Kliewer (1998) observed the school literacy experiences of 10 children with Down syndrome who were included in regular preschool and elementary classrooms over a 2-year period. Six of the students were either completely separated from the literacy community of the regular classroom or limited to participating in "remedial practices that focused on low-level concepts or diminished subskills" (p. 173). The other four students were full participants in classroom literacy activities in which "teachers saw worth in symbols and print as a tool for connecting students to the wider classroom community" (p. 173). Kliewer concluded that physical integration in regular classrooms is not sufficient to ensure literacy development in children with Down syndrome, and argued for a re-definition of literacy that shifts the focus from the attainment of isolated subskills to literacy as a tool for communication.

Research examining literacy development also suggests that home and community literacy events are crucial factors. Studies of the home literacy experiences of children with general intellectual disabilities (Marvin, 1994; Marvin \& Mirenda, 1993; Marvin \& Wright, 1997), severe speech and physical impairments (Light \& Kelford Smith, 1993), visual impairments (Craig, 1996, 1999; Stratton, 1996), and learning disabilities (Rashid, 2002; Scarborough et al., 1991) suggest that individuals in these disability groups share a number of common literacy experiences, especially in their early years. However, almost nothing is known about the relationship between home and community lit- eracy environments and literacy ability in individuals with Down syndrome. The exception is a study that specifically examined the home literacy experiences of three preschool children with Down syndrome through an in-depth analysis of permanent products, tape recorded parent-child interactions, and observations (Fitzgerald et al., 1995). The authors concluded that: (a) although the home environments of the children were print-rich, there were only a modest number of actual literacy events, consisting primarily of storybook reading; (b) during storybook reading, two of the three mothers used a highly interactive style that was conducive to literacy development; and (c) the third mother appeared to have lower expectations for her child with Down syndrome than for her other, typically developing child.

Although there is growing awareness about the potential for people with Down syndrome to become literate, little is known about the literacy events this group experiences. The purpose of this exploratory study was to examine the home and community literacy experiences of individuals with Down syndrome, in order to complement research examining other aspects of literacy development in this population. Specific questions included:

(1) How high is the priority assigned by parents to developing literacy in people with Down syndrome of various ages?

(2) What reading and writing events do people with Down syndrome observe and participate in at home and in the community?

(3) How do parents and other adults interact with people with Down syndrome during reading and writing activities in the home?

(4) What are the beliefs and attitudes of parents/guardians toward the development of reading and writing in individuals with Down syndrome?

\section{Method}

\section{Survey construction}

A 42 -item survey was constructed to gather descriptive information about home and community literacy experiences of individuals with Down syndrome. ${ }^{1}$ The survey consisted of five subsections entitled: Identification Information; Literacy Abilities, Goals, and Resources; Reading; Writing; and Progress and Needs. Survey items were written in checklist and multiple choice formats to facilitate completion in a reasonable amount of time by parents. The face validity of the survey questions was evaluated by two University professors with expertise in reading development and/or special education of individuals with developmental disabilities; and by the executive director and the program and services director of the Down Syndrome Research Foundation (DSRF) in Vancouver, British Columbia (Canada). The survey was edited following these evaluations, and the resulting instrument and a feed-

\footnotetext{
${ }^{1}$ A copy of the survey is available from the second author on request
} 
back form were completed by five parents of children with Down syndrome. All parents indicated that they were able to complete the survey in 15-20 minutes. Based on their feedback, additional revisions were made to the survey to remove redundant questions, clarify wording, and simplify some of the question formats. The five pilot surveys were not included in the study.

\section{Survey distribution}

Survey packages consisted of a letter of invitation from the executive director of the DSRF, a letter from the first author explaining the purpose of the research and inviting participation, the survey itself, and a self-addressed stamped envelope. Participants in the survey were eligible to have their names entered into a lottery for a gift certificate at a local bookstore and a copy of Teaching Reading to Children with Down Syndrome (Oelwein, 1995).

A total of 418 parents or guardians of children with Down syndrome were identified and contacted in cooperation with the DSRF. Eighty-six surveys were distributed to parents who attended the Canadian Down Syndrome Society's $15^{\text {th }}$ annual conference (2003) in Vancouver, BC. An additional 332 surveys were mailed to parents or guardians who were either DSRF members or who had registered with the Canadian Population Registry for Individuals with Down Syndrome. Recipients of the mailed surveys received followup reminder postcards one week after the initial mailing. The return rate was $50 \%$ (i.e., 43 out of 86 surveys) for conference attendees and $54.5 \%$ (i.e., 181 out of 332 surveys) for mailed surveys. The overall return rate was $53.6 \%$ (i.e., 224 out of 418 surveys).

\section{Participants}

The demographic characteristics of respondents and their children with Down syndrome are summarised in Table 1.

The respondents were categorised into five groups, according to the age of the person with Down syndrome who was the focus of each survey. The five groups included persons with Down syndrome aged (years:months): 0 to 5:0 ( $\mathrm{n}=$ $42) ; 5: 1$ to $9: 0(\mathrm{n}=56) ; 9: 1$ to $13: 0(\mathrm{n}=49) ; 13: 1$ to $19: 0$ $(\mathrm{n}=36)$; and 19:1 to $41: 11(\mathrm{n}=41)$. Gender representation was approximately equal except in the $9: 1$ to $13: 0$ group (70.2\% males) and the $19: 1$ to $41: 11$ group $(73.2 \%$ males $)$.

For all but one group, $100 \%$ of the respondents were parents; in the 19:1 to $41: 11$ age group, approximately $5 \%$ were guardians or caregivers. In all categories, at least $75 \%$ of the respondents were mothers. English was the primary language in $91.7 \%$ to $98.3 \%$ of the respondents' homes across all five age categories. The reported use of languages other than English ranged from 1.7\% to 8.3\% and included Cantonese, French, Korean, Mandarin, and Thai.

Respondents' occupational status and educational level were classified using a modification of the Hollingshead Four Factor Index of Social Status (as described in Scheider, 1986). In this modification, scores of 1-9 were assigned to each occupation, with $\mathrm{l}=$ unemployed and $9=$ executives, professionals, or large business owners. Scores of 1 to 11 were assigned with regard to years of education, with 1 = elementary school and $11=$ doctorate or equivalent (e.g., M.D.). A mean family classification was determined for both occupational status and educational level by calculating the average scores for each variable in two-parent households. Occupational status was high and homogenous across the five groups. The mean parent occu-

Table I. Demographic characteristics of people with Down syndrome represented in the sample (Percentages)

\begin{tabular}{|c|c|c|c|c|c|c|c|c|c|c|c|c|}
\hline \multirow{2}{*}{$\begin{array}{l}\text { Age in years: } \\
\text { months }\end{array}$} & \multicolumn{2}{|c|}{$\begin{array}{l}\text { Primary } \\
\text { Language }\end{array}$} & \multirow{2}{*}{$\begin{array}{l}\text { M Family } \\
\text { Occup. }^{\text {a }}\end{array}$} & \multirow{2}{*}{$\begin{array}{l}\text { M Family } \\
\text { Educ. }\end{array}$} & \multicolumn{3}{|c|}{ Canadian Province } & \multicolumn{2}{|c|}{ Gender } & \multicolumn{3}{|c|}{$\begin{array}{c}\text { Communication of People } \\
\text { with DS }\end{array}$} \\
\hline & English & Other & & & $B C^{c}$ & ONc & Other & Male & Female & Speech & Gesture & Sign \\
\hline $\begin{array}{l}\text { Up to } 5: 0 \\
n=42\end{array}$ & 92.3 & 7.7 & $\begin{array}{l}\text { Skilled } \\
\text { Worker }\end{array}$ & Some Univ. & 41.0 & 41.0 & 18.0 & 51.3 & 48.7 & 61.5 & 71.8 & 69.2 \\
\hline $\begin{array}{l}5: 1 \text { to } 9: 0 \\
n=56\end{array}$ & 98.3 & 1.7 & $\begin{array}{l}\text { Skilled } \\
\text { Worker }\end{array}$ & Some Univ. & 43.1 & 44.8 & 12.1 & 46.6 & 53.4 & 89.3 & 57.1 & 35.7 \\
\hline $\begin{array}{l}9: 1 \text { to } 13: 0 \\
n=49\end{array}$ & 97.9 & 2.1 & $\begin{array}{l}\text { Skilled } \\
\text { Worker }\end{array}$ & Some Univ. & 51.1 & 38.3 & 10.6 & 70.2 & 29.8 & 97.2 & 59.6 & 23.4 \\
\hline $\begin{array}{l}13: 1 \text { to } 19: 0 \\
n=36\end{array}$ & 91.7 & 8.3 & $\begin{array}{l}\text { Skilled } \\
\text { Worker }\end{array}$ & Some Univ. & 40.5 & 37.8 & 21.7 & 40.5 & 49.5 & 94.6 & 56.8 & 10.8 \\
\hline $\begin{array}{l}\mid 9: I \text { to } 4 I: I I \\
n=4 \mid\end{array}$ & 92.7 & 7.3 & $\begin{array}{l}\text { Skilled } \\
\text { Manual } \\
\text { Worker }\end{array}$ & College & 43.9 & 36.6 & 19.5 & 73.2 & 26.8 & 100.0 & 48.8 & 2.4 \\
\hline
\end{tabular}

${ }^{a}$ Occupation is the mean across both parents, using the Hollingshead Socio-Economic Status Occupational Factor (as described in Scheider, 1986).

${ }^{b}$ Education is the mean number of years across both parents.

${ }^{\mathrm{C}} \mathrm{BC}=$ British Columbia; $\mathrm{ON}=$ Ontario 
pational category of skilled worker (Hollingshead score $=5$ ) occurred in all categories, with the exception of the 19:1 to $41: 11$ age group, where the mean category was skilled manual worker (Hollingshead score $=4$ ). The mean parent educational level across the five groups was also high and homogeneous. The educational level classification of some university (Hollingshead score $=6$ ) was observed in all categories, with the exception of the 19:1 to 41:11 age group where the mean educational level was college (Hollingshead score $=5$ ).

Surveys were returned from diverse Canadian geographic locations. Approximately equal numbers were returned from parents in British Columbia and Ontario; depending on the age category, these accounted for between $78.3 \%$ and $89.4 \%$ of all returns. Surveys were also returned from six other provinces and territories and accounted for between $10.6 \%$ and $21.7 \%$ of the returns, depending on the age category.

On the survey, respondents were asked to indicate the two main ways their child with Down syndrome communicated in the home. Approximately $90 \%$ or more of all individuals with Down syndrome except for those in the youngest age group $(61.5 \%)$ were reported to use speech to communicate. The use of gestures was most frequent in the youngest age group $(71.8 \%)$ and least frequent in the adult group $(48.8 \%)$. The use of manual sign language was approximately the same as gestures $(69.2 \%)$ in the youngest age group but was infrequent in the $13: 1$ to $19: 0$ group $(10.8 \%)$ and in the adult group (2.4\%).

\section{Data analysis and reliability}

Descriptive statistics for the survey data were calculated using the Statistical Package for the Social Sciences (SPSS, Inc., 2000). Frequencies and percentages were used to describe the demographic characteristics of participants and their children with Down syndrome according to age, gender, education, occupational status, educational level, province of residence, and primary language at home. Means, frequencies, and percentages were also calculated to describe the literacy experiences of individuals with Down syndrome. Linear regressions were calculated to examine whether total parent occupation score and/or total parent education score predicted the expected reading/writing abilities of individuals with Down syndrome.

Intra-rater reliability for survey coding and data entry was calculated by recoding and re-entering $10 \%$ of the surveys and calculating the percent agreement using the formula: agreements divided by (agreements + disagreements) multiplied by 100 . Intra-rater reliability was $99.8 \%$. All errors were corrected before data analysis. with Down syndrome

\section{Results}

Because of the broad age range (3:3 to $41: 11)$ of the persons with Down syndrome represented in the surveys, data were analysed both for the total sample and for the five age subgroups. The data are presented for the entire sample only, except when differences across age groups were apparent.

\section{Literacy goals, interests, and priorities}

\section{Respondents' goals for their children with Down syndrome}

Respondents were asked to rank their three "top priority" goals for their children at the time of the survey, from 1 (most important) to 3 . Table 2 summarises the results by age group, with the goals selected by more than $50 \%$ of respondents highlighted in boldface type.

Communicating effectively, learning self-help skills, and making friends were the goals most frequently ranked in the top three. The development of vocational skills was ranked as important by $58.6 \%$ of respondents for the adult age group. Learning to read was chosen by $56.3 \%$ for the $5: 1$ to $9: 0$ group and by $62.1 \%$ for the $9: 1$ to $13: 0$ group. Less than one-third of respondents ranked learning to read as one of the three most important goals for the other three age groups. Across all age groups, less than $25 \%$ of respondents ranked learning to write as a high priority goal.

\section{Interest in learning to read and write}

Although the respondents ranked neither learning to read nor learning to write as top priority goals for their children with Down syndrome, over $70 \%$ indicated that their children with Down syndrome themselves were either very or somewhat interested in learning to read. Similarly, over 70\% of respondents for all except the youngest age group indicated that their children were very or somewhat interested in learning to write. For the three youngest age groups, more than $80 \%$ of respondents indicated that their children with Down syndrome were either very or somewhat interested in drawing, while over $50 \%$ of respondents indicated this for the two oldest age groups.

Table 2. Percentage of respondents ranking an area as a 'Top Three' priority for their child

\begin{tabular}{lccccc}
\hline & \multicolumn{5}{c}{ Age Group } \\
Area & Up to 5:0 & 5:I to 9:0 & 9:I to I3:0 & I3:I to 19.0 & 19.1 to 4I:II \\
\hline Communication & $\mathbf{9 7 . 3}$ & $\mathbf{9 1 . 7}$ & $\mathbf{8 1 . 1}$ & $\mathbf{5 7 . 6}$ & $\mathbf{6 4 . 8}$ \\
Self-help & $\mathbf{7 7 . 8}$ & $\mathbf{5 6 . 3}$ & $\mathbf{5 4 . 0}$ & $\mathbf{6 6 . 6}$ & 43.1 \\
Making friends & $\mathbf{5 5 . 5}$ & $\mathbf{5 2 . 0}$ & 32.4 & $\mathbf{5 7 . 6}$ & 37.2 \\
Reading & 30.5 & $\mathbf{5 6 . 3}$ & $\mathbf{6 2 . 1}$ & 27.3 & 28.0 \\
Writing & 8.4 & 18.8 & 24.3 & 12.2 & 9.4 \\
Recreational skills & 8.4 & 12.5 & 18.9 & 24.2 & 37.4 \\
Knowledge of the world & 5.6 & 6.3 & 10.8 & 12.1 & 18.6 \\
Vocational skills & 0.0 & 2.1 & 8.1 & 36.4 & $\mathbf{5 8 . 6}$
\end{tabular}


Table 3. Percentage of respondents reporting the level of priority given to reading and writing instruction in school and in adulthood

\begin{tabular}{|c|c|c|c|c|c|c|c|c|c|c|}
\hline \multirow[b]{2}{*}{$\begin{array}{l}\text { Age in years: } \\
\text { months }\end{array}$} & \multicolumn{2}{|c|}{ K-Grade 3} & \multicolumn{2}{|c|}{ Grade 4-6 } & \multicolumn{2}{|c|}{ Grade 7-9 } & \multicolumn{2}{|c|}{ Grade $10-12$} & \multicolumn{2}{|c|}{ Adulthood } \\
\hline & $\begin{array}{l}\text { High- } \\
\text { mod }\end{array}$ & $\begin{array}{c}\text { Low-very } \\
\text { low }\end{array}$ & $\begin{array}{l}\text { High- } \\
\text { mod }\end{array}$ & $\begin{array}{c}\text { Low-very } \\
\text { low }\end{array}$ & $\begin{array}{l}\text { High- } \\
\text { mod }\end{array}$ & $\begin{array}{c}\text { Low-very } \\
\text { low }\end{array}$ & $\begin{array}{l}\text { High- } \\
\text { mod }\end{array}$ & $\begin{array}{c}\text { Low-very } \\
\text { low }\end{array}$ & $\begin{array}{l}\text { High- } \\
\text { mod }\end{array}$ & $\begin{array}{c}\text { Low-very } \\
\text { low }\end{array}$ \\
\hline Up to $5: 0$ & $\mathrm{~N} / \mathrm{A}$ & N/A & & & & & & & & \\
\hline $5: 1$ to $9: 0$ & 69.8 & 24.5 & & & & & & & & \\
\hline $9: 1$ to $13: 0$ & 70.0 & 27.5 & 71.7 & 15.2 & 8.6 & 2.1 & & & & \\
\hline $13: 1$ to $19: 0$ & 75.8 & 24.3 & 84.9 & 9.1 & 67.7 & 17.7 & 29.0 & 9.7 & & \\
\hline $19: \mid$ to $41: 1 \mid$ & 79.5 & 20.6 & 89.8 & 10.3 & 75.6 & 24.3 & 47.3 & 50.0 & 51.2 & 36.6 \\
\hline
\end{tabular}

\section{Priority given to learning to read and write in school}

Respondents were also asked to indicate the priority they believed was given to reading and writing instruction for their children at school and in adulthood. Table 3 summarises their responses to this question. Percentages in excess of $50 \%$ are highlighted in boldface type.

For all age groups, $68 \%$ or more of respondents indicated that reading and writing instruction were given either moderate or high priority at school in grades $\mathrm{K}$ through 9. Fewer than $50 \%$ of respondents reported that reading and writing instruction was given either moderate or high priority in grades 10 through 12. Approximately one-half of respondents whose children with Down syndrome were adults reported that reading and writing instruction were moderate or high priorities.

\section{Reading abilities and experiences}

\section{Reading ability estimates}

Table 4 presents the reported reading ability of individuals with Down syndrome according to age. The highest percentages in each age group are highlighted in boldface type.
Most children in the youngest age group $(75.7 \%)$ were reported as unable to read, although $21.6 \%$ were able to recognise letters. In the 5:1 to 9:0 age group, approximately one-third $(31.1 \%)$ were reportedly unable to read, while approximately $28.9 \%$ could read simple text or text at a grade 1 level. Children aged 9:1 to 13:0 demonstrated a broad range of abilities, with $28.9 \%$ described as reading at a grade 1-2 level. Higher ability levels were reported for the two oldest age groups. In the 13:1 to 19:0 group, approximately $30 \%$ of individuals with Down syndrome were reported to be reading at either a grade $1-2$ or grade 3-4 level. In the adult group, approximately $80 \%$ were described as reading between a grade 1 and grade 6 level, with the largest percentage $(47.1 \%)$ reading at a grade $3-4$ level.

\section{Reading materials observed and used by people with Down syndrome at home}

Survey questions were included to identify the reading materials people with Down syndrome observed being used by others in the home as well as the materials they themselves used. Nineteen different types of reading materials were listed, ranging from standard print media such as books, newspapers, and magazines to electronic media such as e-mails and closed caption television. Although more than $50 \%$ of respondents reported that 16 different types of reading materials were used by family members at home, only storybooks $(66.7 \%)$, picture books $(62.3 \%)$, and computers $(52.7 \%)$ were reportedly used by more than half of individuals with Down syndrome themselves.

\begin{tabular}{|c|c|c|c|c|c|c|c|c|c|c|}
\hline Age in years:months & $\begin{array}{l}\text { Does not } \\
\text { read }\end{array}$ & $\begin{array}{l}\text { Recognises } \\
\text { letters }\end{array}$ & $\begin{array}{l}25-50 \\
\text { words }\end{array}$ & $\begin{array}{l}\text { Simple } \\
\text { text }\end{array}$ & $\begin{array}{l}\text { Grade } \\
\mathrm{I}-2\end{array}$ & $\begin{array}{l}\text { Grade } \\
3-4\end{array}$ & $\begin{array}{l}\text { Grade } \\
5-6\end{array}$ & $\begin{array}{l}\text { Grade } \\
7-8\end{array}$ & $\begin{array}{l}\text { Grade } \\
9-10\end{array}$ & $\begin{array}{l}\text { Grade } \\
11-12\end{array}$ \\
\hline Up to $5: 0$ & 75.7 & 21.6 & 2.7 & 0.0 & 0.0 & 0.0 & 0.0 & 0.0 & 0.0 & 0.0 \\
\hline $5: 1$ to $9: 0$ & 31.1 & 28.9 & 8.9 & 26.7 & 2.2 & 2.2 & 0.0 & 0.0 & 0.0 & 0.0 \\
\hline $9: 1$ to $13: 0$ & 7.9 & 7.9 & 13.2 & 26.3 & 28.9 & 13.2 & 2.6 & 0.0 & 0.0 & 0.0 \\
\hline $13: 1$ to $19: 0$ & 2.9 & 2.9 & 8.8 & 8.8 & 29.4 & 29.4 & 14.7 & 0.0 & 0.0 & 2.9 \\
\hline $19: \mid$ to $41: 11$ & 0.0 & 2.9 & 2.9 & 5.9 & 20.6 & 47. & 14.7 & 5.9 & 0.0 & 0.0 \\
\hline
\end{tabular}


While the range of materials read by individuals with Down syndrome was quite narrow, $55.2 \%$ of respondents reported that their children used these materials to read "many times" per day. An additional $21.2 \%$ reported that their children with Down syndrome read once per day, and $10.8 \%$ reported a frequency of 4 to 5 times per week. The frequency with which individuals with Down syndrome were read to by others was somewhat less, with $24 \%$ read to many times per day and $28.1 \%$ reportedly read to once daily.

The largest percentage $(68.3 \%)$ of respondents reported spending less than 15 minutes per day discussing what was read with their child. More than one-half of respondents reported that they typically read text out loud (67.4\%), pointed to pictures and labels $(58.3 \%)$, and/or pointed to words $(55 \%)$ as they read to their children. Other common supports included asking the person with Down syndrome to label $(46.8 \%)$ or point to pictures $(45.9 \%)$. More complex types of interactions, such as asking what happened in the story, asking the person with Down syndrome to predict what would happen next, asking the person with Down syndrome to re-tell a story in his/her own words, and asking why something happened were each reported by approximately $25 \%$ of respondents or less. Few respondents $(8.7 \%)$ reported that their children with Down syndrome were never read to at home.

\section{Literacy activities in the community}

As an indicator of literacy use in the community, respondents were asked to comment on use of the public or school library by their children with Down syndrome. From a list of 15 potential library activities, only going to the library with family members (70.9\%) and borrowing books (65.5\%) were identified by the majority of respondents. Several additional activities, including reading, borrowing CDs/ audiotapes, initiating going to the library, and using library computers, were identified by $20 \%$ to $25 \%$ of respondents.

\section{Writing abilities and experiences}

\section{Writing ability estimates}

Table 5 presents the reported writing ability of individuals with Down syndrome according to age, excluding the 0 to 5:0 age group, in which no individuals were able to write. The largest percentages in each age group are highlighted in boldface type.

As might be expected, the writing abilities of individuals with Down syndrome appeared to increase as a function of age. Many children in the 5:1 to 9:0 age group were reportedly able to write their names or other familiar words $(46.4 \%)$ or to write in workbooks $(25 \%)$, but few engaged in other writing activities. Those in the 9:1 to 13:0 group were reported to have a broader range of writing abilities, with over half able to write or copy their names or familiar words $(69.6 \%)$ and/or write in workbooks (52.2\%). Individuals with Down syndrome in the 13:1 to 19:0 age group had an even wider variety of writing skills, including the ability to write their names or familiar words (59.5\%), write in workbooks $(62.2 \%)$, and/or write simple answers to questions $(51.4 \%)$. Those in the adult age group were also reported to display a broad range of writing abilities, although the nature of those abilities changed relative to the other groups. Respondents mentioned functional activities such as making lists $(65.9 \%)$ and writing notes to relay messages $(68.3 \%)$ most often, in addition to writing names or other familiar words $(68.3 \%)$. The ability to participate in school-based writing activities that involved workbooks $(46.3 \%)$ and writing simple answers to questions $(39 \%)$ were mentioned less often for the adults.

\begin{tabular}{|c|c|c|c|c|}
\hline \multirow[b]{2}{*}{ Writing ability } & \multicolumn{4}{|c|}{ Age of Person with Down syndrome in years:months } \\
\hline & $5: 1$ to $9: 0$ & $9: 1$ to $13: 0$ & $13: 1$ to $19: 0$ & $19: 1$ to $41: 11$ \\
\hline Writes/copies name/familiar words & 46.4 & 69.6 & 59.5 & 68.3 \\
\hline Writes in workbooks & 25.0 & 52.2 & 62.2 & 46.3 \\
\hline Writes school assignments & 7.1 & 30.4 & 37.8 & 34.1 \\
\hline Writes in journal & 5.4 & 30.4 & 43.2 & 39.0 \\
\hline Writes e-mail & 3.6 & 8.7 & 37.8 & 41.5 \\
\hline Writes simple answers to questions & 1.8 & 30.4 & 51.4 & 39.0 \\
\hline Writes notes to relay messages & 1.8 & 15.2 & 45.9 & 68.3 \\
\hline Writes lists & 1.8 & 26.1 & 45.9 & 65.9 \\
\hline Writes letters & 1.8 & 15.2 & 37.8 & 41.5 \\
\hline Writes in time organizer & 0.0 & 8.7 & 16.2 & 34.1 \\
\hline Completes forms & 0.0 & 2.2 & 16.2 & 34.1 \\
\hline Writes postcards & 0.0 & 4.3 & 13.5 & 24.4 \\
\hline Does not write & 37.5 & 4.3 & 2.7 & 0.0 \\
\hline
\end{tabular}




\section{Writing and drawing materials observed and used by people with Down syndrome at home}

As with reading materials, respondents reported that a wide range of writing materials were observed being used in the home. Use of pencils/pens and paper (99.1\%), computers $(92.4 \%)$, crayons or magic markers $(83.9 \%)$, calculators (76.8\%), and paintbrushes or paints $(56.7 \%)$ were reported in a majority of the respondents' homes. For children with Down syndrome in the youngest age group, drawing pictures with a pencil or marker $(82.1 \%)$ was the only activity reported by the majority of respondents. For the 5:1 to 9:0 group, more than half of respondents reported that their children drew pictures with a pencil or marker $(91.2 \%)$, played with writing toys $(64.9 \%)$, chose writing or drawing activities $(61.4 \%)$, and copied letters or words $(59.6 \%)$. Similarly, a majority of respondents with children in the 9:1 to $13: 0$ group reported that they drew pictures with a pencil or marker $(78.7 \%)$ and copied letters or words (68.1\%). They also reported a broader scope of activities overall, which likely reflects the changing nature of school tasks and expectations. For example, use of calculators $(46.8 \%)$; grammar and spelling worksheets $(40.4 \%)$; and both pens $(46.8 \%)$ and computers $(31.9 \%)$ for independent writing were all reported more often for 9:1 to 13:0 year olds than for 5:1 to 9:0 year olds.

Respondents for children in the two oldest age groups also reported a broad range of writing/drawing activities. Adolescents with Down syndrome (i.e., those in the 13:1 to 19:0 age group) reportedly drew pictures with pens or markers $(62.2 \%)$, used calculators $(64.9 \%)$, copied letters or words $(81.1 \%)$, completed grammar or spelling worksheets $(51.4 \%)$, and wrote independently with pens (62.2\%). Not surprisingly, those in the adult (i.e., 19:1 to 4l:11) age group engaged in more "functional" than school-based activities, including using calculators (53.7\%), copying letters or words (51.2\%), and using pens $(58.5 \%)$ and/or computers $(51.2 \%)$ to write independently.

Forty-six percent of respondents reported that their children with Down syndrome were involved in writing activities once per day, and approximately $30 \%$ reported that these activities occurred between 0 to 3 times per week. Almost half (46.8\%) indicated that their children with Down syndrome typically wrote or drew for less than 15 minutes at a time, and an additional $32.9 \%$ reported durations of between 15 to 30 minutes. More than $75 \%$ of respondents for all age groups except adults reported that family members typically encouraged persons with Down syndrome to write more and commented on their writing/drawing at home. A majority of respondents with children in the youngest and the 5:1 to 9:0 age groups also indicated that someone often provided hand-over-hand guidance and/or assisted the person with Down syndrome to position a writing instrument properly. A majority of respondents for the three oldest age groups (i.e., ages 9:1 to 13:0 and older) reported spelling words out loud for their children, and those with adolescent or adult children reported that they answered questions during writing activities as well.

\section{Resources, barriers, needs, and progress}

\section{Utilisation of community resources}

One-quarter to one-third of respondents indicated that they had contacted a school or public librarian and/or had utilised the general library collection within the last 6 months with regard to their child's literacy development. Almost one-third (30.8\%) indicated that they had not contacted any literacy resources. In contrast, fewer than $10 \%$ reported that they had contacted or utilised either private or peer literacy tutors, continuing education programs, free or fee-for-service literacy programs, provincially-funded literacy programs, or the adult basic education collection at a library.

\section{Barriers to literacy development}

Respondents were also asked to identify perceived barriers to their children's literacy development from a list of 15 possible barriers, with the option of adding to the list if necessary. Table 6 summarises the results related to literacy barriers.
Table 6. Percentage of respondents identifying specific barriers to literacy development

\begin{tabular}{lc}
\hline Barrier & Percentage \\
\hline Lack of literacy programs & 19.0 \\
Expectations in literacy programs are too low & 19.0 \\
Lack of information about literacy programs & 18.5 \\
Person with Down syndrome is not interested in reading or writing & 17.1 \\
Lack of knowledge by others about reading and writing & 12.8 \\
Too many other interests by person with Down syndrome & 11.8 \\
Family members do not have time to join in literacy activities & 11.4 \\
Literacy programs are too expensive & 6.6 \\
Literacy program content is too easy or too hard & 4.7 \\
Transportation issues that prevent attendance at literacy programs & 4.3 \\
Literacy program expectations are too high & 4.3 \\
Literacy materials are too expensive & 2.8 \\
Literacy programs are too short & 2.8 \\
Time between literacy programs is too long & 2.4 \\
Lack of books & 0.9 \\
\hline
\end{tabular}


Seven of the 15 barriers listed on the survey were chosen by $10 \%$ or more of respondents. Given the sample size, this indicates that approximately 20 or more respondents identified these barriers as significant. A lack of literacy programs (19.0\%), low expectations in existing programs (19.0\%), and lack of information about programs (18.5\%) were the three most frequently mentioned barriers. Lack of interest in reading and writing by the person with Down syndrome (17.1\%), lack of knowledge about reading and writing by others $(12.8 \%)$, too many competing interests for the person with Down syndrome (11.8\%), and lack of time by family members (11.4\%) were the also selected by more than $10 \%$ of respondents.

\section{Interventions needed for literacy development}

Two-thirds of respondents indicated that parent training in teaching reading (35.4\%) and/or writing (29.7\%) would be helpful interventions. In addition, almost two-thirds indicated that literacy programs that convened either 1 to 2 times per week $(17.7 \%)$ or 3 or more times per week $(41.1 \%)$ would be helpful. Private tutoring $(33.5 \%)$ and/or peer tutoring $(20.6 \%)$ were also selected by a majority of respondents. Receiving suggestions from their child's current teacher was identified as a potentially helpful intervention by $20.6 \%$ of respondents.

\section{Literacy expectations}

The survey included an item in which respondents were asked to indicate the age(s) at which they believed persons with Down syndrome are likely to make the most progress in learning to read and write. The age range from 6 to 12 was selected most often by respondents for both reading $(55.8 \%)$ and writing $(48 \%)$. Approximately one-third indicated that they believed the most progress would be made by people with Down syndrome between 13 to 19 years old age in reading (32\%) and writing $(36.8 \%)$. Less than $10 \%$ felt the optimum progress would occur during the adult years, and more than one-quarter of respondents indicated that they did not know the answer to this question.

Respondents were also asked to estimate their expectations with regard to the future reading and writing abilities of their children with Down syndrome. Half of the respondents indicated that they expected their children with Down syndrome to be able to read newspapers, magazines, and/or novels. In addition, $55 \%$ expected them to be able to write letters and stories. An additional $15.1 \%$ believed that their children with Down syndrome would be able to read and write sufficiently to be competitive in a college or university classroom. Only $3.7 \%$ believed that their children would not be able to read at least some sight words.

Linear regressions were calculated to examine whether total parent occupation score and/or total parent education score predicted parents' expectations of the future reading and/ or writing abilities of their children with Down syndrome. The total parent education score was determined by adding the education level score for each respondent and his/her spouse. The total parent occupation score was determined by adding scores of the respondent and his/her spouse using a modification of the Hollingshead Socio-Economic Status Occupational Factor scale (as described in Scheider, 1986). None of the regressions were significant. For reading, $\mathrm{R}$ square $=.003(p=.48)$ for parent occupation and $\mathrm{R}$ square $=.014(p=.12)$ for parent education. For writing, $\mathrm{R}$ square $=.001(p=.77)$ for occupation and $\mathrm{R}$ square $=.014$ $(p=.15)$ for education. Thus, neither total family occupation nor total family education predicted parent expectations related to reading and writing.

\section{Discussion}

\section{Learning to read vs Reading to learn}

Not surprisingly, the survey results provide evidence that children with Down syndrome lag far behind their typically developing peers at all reading levels. It is interesting to consider these results in the context of Chall's (1983) descriptions of the stages of literacy development. The findings suggest that the transition from 'learning to read' to 'reading to learn' (i.e., at least grade 4 reading ability) occurred for approximately $15 \%$ of the adolescents and adults with Down syndrome whose parents completed the survey. In addition, $5 \%$ of the 5:1 to 9:0 year age group and approximately $50 \%$ of the 9:1 to $13: 0$ year age group were estimated to read between school grades 1 to 4 . These estimates are generally consistent with previous estimates found in the small body of research concerned with reading achievement in children with Down syndrome (e.g., Buckley, 1985; Fowler et al., 1995; Oelwein, 1995). Of course, the reading ability estimates in this survey must be interpreted with caution, since the data were reported by parents and grade level definitions were not provided in the survey.

Overall, the results indicate that most parents of children with Down syndrome provide many opportunities for them to observe others using a broad range of literacy materials at home and in the community. This is congruent with Marvin and Wright's (1997) suggestion that lack of exposure to print materials is unlikely to be a major factor limiting the reading and writing abilities of people with disabilities. On the other hand, the breadth of reading materials actually used at home and in the community (e.g., the public library) by people with Down syndrome themselves was quite narrow. In addition, although a majority of respondents indicated that they read text to their children and pointed to and/or labeled pictures, much smaller percentages $(20 \%$ to $30 \%)$ reported that they either asked their child to re-tell a story or asked questions about what happened in the story, what would happen next, and/or why something happened. That these higher-order reading interactions appeared to receive less attention suggests that some parents of children with Down syndrome might benefit from knowing more about how these types of questions appear to enhance reading development (Marvin \& Wright, 1997). 


\section{Learning to write}

According to respondents' reports, children with Down syndrome also lag behind typical children in the area of writing, and involvement in writing activities was quite limited for a substantial minority. Across age groups, the data appeared to reflect generally favourable circumstances for individuals with Down syndrome learning to write for basic academic and practical purposes only. Somewhat analogous to Chall's (1983) description of the limitations of functionally illiterate readers, the increased emphasis on functional writing skills in adults with Down syndrome suggests that many are able to write primarily familiar text that does not extend beyond their existing knowledge and vocabulary. Overall, respondents reported that their children with Down syndrome saw others in their home using a wide range of writing materials and that they also used a variety of these materials to engage in actual writing tasks that appeared suited to their chronological ages. Thus, as was the case for reading, limited access and/or exposure to a wide variety of writing materials did not appear to be a factor that could account for individuals with Down syndrome failing to develop a broad range of writing abilities. However, less than one-half of respondents indicated that their children wrote one or more times per day, and the duration of writing activities was reported to be less than 15 minutes per day for approximately half. This suggests that the frequency of home writing activities may be a concern.

\section{Goals and expectations}

Previous studies of home literacy experiences have found that parental goals and expectations regarding literacy development differ considerably between parents of children with disabilities and parents of typically developing children. For example, Marvin and Wright (1997) compared the top priority goals of parents of children with speech language impairments (SLI), children with other disabilities but no speech language impairments (NSLI), and children with no disabilities (ND). Parents with SLI children chose communicating effectively as a top priority goal significantly more often than parents in the other two groups, while parents in the NSLI group chose developing self-help skills significantly more often. In contrast, parents of children in the ND group chose learning to write, making friends, and increasing world knowledge significantly more often than parents in the other two groups. Light and Kelford Smith (1993) reported that parents of typical preschoolers prioritised literacy activities higher than parents of preschoolers with physical disabilities who use augmentative communication devices. Marvin (1994) examined the priorities of parents whose children had either single or multiple disabilities and found that less than half of respondents in both groups selected learning to read and write as top priority goals. Similarly, Marvin and Mirenda (1993) compared the priority goals of parents of preschoolers with disabilities, 'at risk' preschoolers, and typical preschoolers. They reported that the top three priority goals of parents of preschoolers with disabilities were communicating effectively, learning self-help skills and making friends. Across these studies, the common element is that, at least for young children with disabilities, learning to read and learning to write are both prioritised consistently lower by parents than communicating effectively, learning self-help skills, and making friends.

In the present study, a majority of respondents identified learning to read as one of the top three goals in the 5:1 to 9:0 (56.3\%) and the $9: 1$ to $13: 0$ age groups $(62.1 \%)$, while a smaller but notable number identified learning to write as a top three goal in the $5: 1$ to $9: 0(18.8 \%)$ and the 9:1 to $13: 0(24.3 \%)$ groups. In all other age groups, learning to read was rated as a priority goal by approximately $30 \%$ of respondents and learning to write was similarly rated by approximately $10 \%$ of respondents. This suggests that there was a relatively narrow range between 5 to 13 years of age when these respondents considered learning to read and write as high priority goals. This is consistent with the survey results indicating that $55.8 \%$ of respondents believed that children with Down syndrome make the most progress in learning to read between the ages of 6 to 12 and that $48.0 \%$ believed this to be the optimum age for learning to write.

That the period during which literacy is considered a priority goal is relatively brief, and that respondents estimate that the most progress in learning to read and write occurs between 6 to 12 years of age raises two concerns. First, home literacy activities that encourage children with Down syndrome to read and write may not begin early enough in some families (i.e., before the age of 6). Second, efforts to teach children to read and write may not be sustained long enough (i.e., after the age of 12). Not only was respondents' priority for learning to read and write low for the two oldest age groups, but school priority for literacy was also reported to decline after grade 6 ; fewer than $50 \%$ of respondents indicated that a high/moderate priority was given in grades 10-12. This is a particular concern given recent data suggesting that adolescence and early adulthood might actually be the optimal time for many individuals with Down syndrome to learn to read and write (e.g., Boudreau, 2002; Fowler et al., 1995; Moni \& Jobling, 2000, 2001).

\section{Barriers and needs}

A lack of literacy programs, low expectations in existing programs, and lack of information about programs were the three most frequently cited barriers and were identified by approximately $20 \%$ of respondents. All three of these barriers are related to some aspect of literacy programs, and together suggest that a substantial number of parents have serious concerns about both the availability and the effectiveness of such programs in their communities. Presented with a list of potential interventions that might foster literacy, a total of $65.1 \%$ of respondents indicated that either parent training in reading $(35.4 \%)$ or writing $(29.7 \%)$ would be helpful, while $58.8 \%$ indicated that a literacy program available to their child with Down syndrome at least once per week would be helpful. Currently, few evidence- 
based curricular materials designed specifically for individuals with Down syndrome are available to either parents or teachers. In addition, the relatively low utilisation of community literacy resources in the six months prior to survey completion appears inconsistent with the large number of respondents $(18.5 \%)$ identifying lack of information about literacy programs as a barrier, and the large number $(65.1 \%)$ who identified parent training in reading or writing as a potentially helpful intervention to foster literacy in individuals with Down syndrome. This suggests that either many people are unaware of the available community literacy resources or that the services provided by these resources are not seen by families as relevant. In either case, outreach by the relevant organisations appears to be needed.

The results of this research should be interpreted cautiously in light of several limitations. First, the data are based on self-reports and might not reflect the actual literacy reading and writing experiences of the focus individuals with Down syndrome. For respondents commenting on older children and adults, self-report data are further limited by the difficulty involved in recalling information about events and perceptions from the distant past. Second, the respondents were not a randomly selected sample of parents with children with Down syndrome. Rather, they included parents who attended the Canadian Down Syndrome Society's $15^{\text {th }}$ annual conference, were members of the Down Syndrome Research Foundation (DSRF), and/or were registrants in the Canadian Population Registry for Individuals with Down syndrome. Also, the overwhelming number of respondents (>95\%) identified English as the primary language in their homes, suggesting that the ethnic and cultural diversity present in Canadian society was not present in the sample. Third, respondents' occupational status and educational levels were relatively homogenous, based on scores assigned using an adaptation of the Hollingshead Four Factor Index of Social Status (as described in Scheider, 1986). The survey sample was relatively highly educated and had middle class occupations.

Despite these limitations, this is the first large-scale exploratory research study to describe the home and community literacy experiences of individuals with Down syndrome. It offers a rich source of information that can be used to generate questions for future research related to literacy development in persons with Down syndrome, and provides a foundation on which to base future research efforts that compare the literacy experience of people with Down syndrome to those of normally developing readers and of other disability groups. The results of this study and others point to the need to establish a sound body of research to guide reading and writing instruction for children and adults with Down syndrome across the lifespan.

\section{Acknowledgements}

This paper is based on a thesis completed by the first author for the degree of Master of Arts in the Faculty of Education at the University of British Columbia. We are grateful to the parents who completed the survey and to Jo Mills and the staff of the Down Syndrome Research Foundation for their support and assistance.

\section{Correspondence}

Pat Mirenda, Ph.D. - Faculty of Education, University of British Columbia, 2I25 Main Mall, Vancouver, BC V6T IZ4,

Canada・Tel: 604-822-6296•E-mail: pat.mirenda@ubc.ca

\section{References}

Al Otaiba, S. \& Hosp, M. (2004). Providing effective literacy instruction to students with Down syndrome. Teaching Exceptional Children, 36, 28-35.

Bochner, S., Outhred, L. \& Pieterse, M. (2001). A study of functional literacy skills in young adults with Down syndrome. International Journal of Disability, Development, and Education, 48, 67-90.

Boudreau, D. (2002). Literacy skills in children and adolescents with Down syndrome. Reading and Writing: An Interdisciplinary Journal, 15, 497-525.

Buckley, S. (1985). Attaining basic educational skills. In D. Lane \& B. Stratford (Eds.), Current Approaches to Down's Syndrome (pp. 315-343). London: Holt, Rinehart and Winston.

Buckley, S. (1995). Teaching children with Down syndrome to read and write. In L. Nadel \& D. Rosenthal (Eds.), Down syndrome: Living and Learning in the Community (pp. 158-169). New York: Wiley-Liss.

Cardoso-Martins, C., Michalick, M. R. \& Pollo, T. C. (2002). Is sensitivity to rhyme a developmental precursor to sensitivity to phoneme?: Evidence from individuals with Down syndrome. Reading and Writing: $A n$ Interdisciplinary Journal, 15, 439-454.

Chall, J. (1983). Stages of Reading Development. New York: McGraw-Hill.

Cossu, G., Rossini, F. \& Marshall, J. C. (1993). When reading is acquired but phonemic awareness is not: A study of literacy in Down's syndrome. Cognition, 46, 129-138.

Craig, C. J. (1996). Family support of the emergent literacy of children with visual impairments. Journal of Visual Impairment \& Blindness, 90, 194-200.

Craig, C. J. (1999). Home literacy experiences of a child with a visual impairment. Journal of Visual Impairment o Blindness, 93, 794-797.

Cupples, L. \& Iacono, T. (2000). Phonological awareness and oral reading skill in children with Down syndrome. Journal of Speech, Language, \& Hearing Research, 43, 595-608.

Cupples, L. \& Iacono, T. (2002). The efficacy of 'whole word' versus 'analytic' reading instruction for children with Down syndrome. Reading and Writing: An Interdisciplinary Journal, 15, 549-574.

Fitzgerald, J., Roberts, J., Pierce, P. \& Schuele, M. (1995). Evaluation of home literacy environment: An illustration with preschool children with Down syndrome. Reading o Writing Quarterly: Overcoming Learning Difficulties, 11, 311-334.

Fletcher H. \& Buckley, S. (2002). Phonological awareness in children with Down syndrome. Down Syndrome Research and Practice, $8,11-18$. 
Fowler, A. E., Doherty, B. J., \& Boynton, L. (1995). The basis of reading skill in young adults with Down syndrome. In L. Nadel \& D. Rosenthal (Eds.), Down Syndrome: Living and Learning in the Community (pp. 182-196). New York: Wiley-Liss.

Gallaher, K. M., van Kraayenoord, C., Jobling, A. \& Moni, K. B. (2002). Reading with Abby: A case study of individual tutoring with a young adult with Down syndrome. Down Syndrome Research and Practice, 8, 59-66.

Gombert, J. (2002). Children with Down syndrome use phonological knowledge in reading. Reading and Writing: An Interdisciplinary Journal, 15, 455-469.

Greene, K. (1987). Involving parents in teaching reading: A project with nine children with Down's syndrome. Mental Handicap, 15, 112-115.

Kennedy, E. J. \& Flynn, M. C. (2003). Early phonological awareness and reading skills in children with Down syndrome. Down Syndrome Research and Practice, 8, 100-109.

Kliewer, C. (1998). Citizenship in the literate community: An ethnography of children with Down syndrome and the written word. Exceptional Children, 64, 167-180.

Light, J. \& Kelford Smith, A. (1993). Home literacy experiences of preschoolers who use AAC systems and of their nondisabled peers. Augmentative and Alternative Communication, 9, 10-25.

Marvin, C. (1994). Home literacy experiences of preschool children with single and multiple disabilities. Topics in Early Childhood Special Education, 14, 436-454.

Marvin, C. \& Mirenda, P. (1993). Home literacy experiences of preschoolers enrolled in Head Start and special education programs. Journal of Early Intervention, 17, 351-367.

Marvin, C. A. \& Wright, D. (1997). Literacy socialization in the homes of preschool children. Language, Speech, and Hearing Services in Schools, 28, 154-163.

Moni, K. B. \& Jobling, A. (2000). LATCH-ON: A program to develop literacy in young adults with Down syndrome. Journal of Adolescent o Adult Literacy, 44, 40-49.

Moni, K. B. \& Jobling, A. (2001). Reading-related literacy learning of young adults with Down syndrome: Findings from a three year teaching and research program. International Journal of Disability, Development \& Education, 48, 377-394.

Morgan, M., Moni, K. B. \& Jobling, A. (2004). What's it all about? Investigating reading comprehension strategies in young adults with Down syndrome. Down Syndrome Research \& Practice, 9, 37-44.

Norris, H. (1989). Teaching Reading to Help Develop Language in Very Young Children with Down's Syndrome. Paper presented at the National Portage Conference, United Kingdom.

Oelwein, P. L. (1995). Teaching Reading to Children with Down Syndrome: A Guide for Parents and Teachers. Bethesda, MD: Woodbine House.

Rashid, L. F. (2002). The influence of home literacy environment on reading achievement in children with reading disabilities. Dissertation Abstracts International, 62(8A), 2683.
Scarborough, H. S., Dobrich, W. \& Hager, M. (1991). Preschool literacy experience and later reading achievement. Journal of Learning Disabilities, 24, 508-511.

Siegel, L. S. (1989). IQ is irrelevant to the definition of learning disabilities. Journal of Learning Disabilities, 22, 469-478, 486.

Snowling, M. J. \& Gombert, J. (2002). Introduction. Reading and Writing: An Interdisciplinary Journal, 15, 433-437.

Snowling, M. J., Hulme, C. \& Mercer, R. C. (2002). A deficit in rime awareness in children with Down syndrome. Reading and Writing: An Interdisciplinary Journal, 15, 471-495.

Spear-Swerling, L. \& Sternberg, R. J. (1996). Off Track: When Poor Readers Become "Learning Disabled." Boulder, CO: Westview Press.

SPSS, Inc. (2000). Statistical Package for the Social Sciences (version 10.1) [Computer software]. Chicago: Author.

Stratton, J. M. (1996). Emergent literacy: A new perspective. Journal of Visual Impairment \& Blindness, 90, 177-183. 